\title{
DIFERENTES OLHARES SOBRE AS PRÁTICAS PEDAGÓGICAS NA LICENCIATURA EM QUÍMICA: UM ESTUDO DE CASO
}

\author{
Carlos Ventura Fonseca* \\ Flávia Maria Teixeira dos Santos ${ }^{* *}$
}

\begin{abstract}
Resumo: Este trabalho apresenta um estudo de caso sobre a formação docente na área de Química. Os objetivos são identificar e problematizar alguns dos elementos que compõem a estrutura curricular e as práticas pedagógicas de um curso de Licenciatura em Química do Rio Grande do Sul. A pesquisa tem como fonte de dados: as visões de docentes e estudantes do curso, investigadas por meio de questionários que foram respondidos por alunos das etapas finais do curso e docentes do Núcleo Docente Estruturante; o projeto pedagógico do curso e documentos que permitem caracterizar e analisar o caso. As disciplinas foram categorizadas com base na literatura, o que possibilitou a determinação das áreas do conhecimento privilegiadas, em termos de carga horária, na estrutura curricular. Os resultados obtidos revelam uma maior similaridade do curso ao modelo da racionalidade técnica, ainda que de forma hibridizada. As evidências também apontam a necessidade de que haja reformulações curriculares que permitam maior interação dos conhecimentos pedagógicos e educacionais com as especificidades dos conhecimentos químicos, permitindo maiores contribuições do curso para o exercício profissional de seus egressos.
\end{abstract}

Palavras-chave: Formação Docente em Química. Currículo. Práticas Pedagógicas.

\section{Introdução}

Nos últimos anos, diversos trabalhos têm elaborado críticas acerca da realidade dos cursos brasileiros de Licenciatura em Química e a epistemologia fragmentadora destes, que separam a aprendizagem dos aspectos pedagógicos dos saberes relativos à especialidade da Química (GAUCHE et al., 2008; ECHEVERRÍA; ZANON, 2010; FONSECA; SANTOS, 2015). A pesquisa brasileira sobre a formação docente em Química aponta a necessidade de que sejam aprofundados os temas da postura profissional crítica e reflexiva, do engajamento do licenciando em atividades de pesquisa voltadas ao ensino durante a graduação (GALIAZZI; MORAES, 2002; MALDANER, 2013; FONSECA; SANTOS, 2016) e a valorização da alfabetização científica para a construção da cidadania (CHASSOT, 2000; SANTOS; SCHNETZLER, 2010).

\footnotetext{
${ }^{*}$ Professor adjunto da Universidade Federal do Rio Grande do Sul (UFRGS), com atuação no Departamento de Ensino e Currículo (DEC) da Faculdade de Educação (FACED). E-mail: carlos.fonseca@ufrgs.br

** Professora Associada da Universidade Federal do Rio Grande do Sul (UFRGS), com atuação no Departamento de Ensino e Currículo (DEC) da Faculdade de Educação (FACED). E-mail: flavia.santos@ufrgs.br
} 
As pesquisas em Educação relativas à formação de professores exploram, principalmente, a formação inicial e sua articulação com o ensino básico (CAMARGO; NARDI, 2007; HILA, 2008; KASSEBOEHMER; FERREIRA, 2008; PINHEIRO; MEDEIROS; OLIVEIRA, 2010; RUSSEL; VEIT, 2011; SILVA; CARVALHO, 2012). As investigações centram-se sobre a vivência de professores novatos (BEJARANO; CARVALHO, 2003), práticas de ensino desafiadoras (GIANOTTO; DINIZ, 2010) e planejamento/avaliação (BARCELOS; VILLANI, 2006).

Análises sobre as políticas educacionais brasileiras também foram formuladas, com destaque para a constituição de um perfil docente utilitarista que exclui o caráter politizado mais amplo da profissão (FREITAS, 2002, 2007; DIAS; LOPES, 2003; MESQUITA; CARDOSO; SOARES, 2013). Outra crítica veemente refere-se às Diretrizes Curriculares Nacionais para a Formação de Professores da Educação Básica - DCNF (BRASIL, 2002a) e sua centralidade no conceito de "competências", que teria fortalecido uma relação determinista entre o desempenho dos alunos e a atuação docente (FREITAS, 2002, 2007; DIAS; LOPES, 2003). Em contrapartida, como ponto positivo desse documento, sinalizam-se a valorização da racionalidade prática (GARCIA; KRUGER, 2009; MESQUITA; CARDOSO; SOARES, 2013) e as reestruturações curriculares em diferentes instituições (GARCIA, 2010; MASSENA; MONTEIRO, 2011). Publicações variadas analisaram propostas específicas inseridas no currículo das licenciaturas, como aquelas focadas na interdisciplinaridade, na resolução de problemas e nos aspectos científico-tecnológicos (SANTOS; INFANTE-MALACHIAS, 2008; PEREIRA et al., 2009; SILVA; FARIAS, 2017).

Os paradigmas da pesquisa-ação e do professor-pesquisador compõem outro eixo de interesse da produção científica brasileira (GALIAZZI; MORAES, 2002; CANEN; ANDRADE, 2005; DURAND; SAURY; VEYRUNES, 2005; LÜDKE; CRUZ, 2005; LENOIR, 2006; SANGIOGO et al., 2011; MALDANER, 2013). Discute-se a possibilidade de que haja melhorias para o fazer profissional docente pela realização da atividade sistemática de pesquisa e da prática reflexiva (ZEICHNER; DINIZ-PEREIRA, 2005; ARRIGO; LORENCINI-JÚNIOR; BROIETTI, 2017), a relação desta com a pesquisa universitária (CANEN; XAVIER, 2005) e a ênfase apresentada pelo texto das DCNF (BRASIL, 2002a) com relação a esse tema (DINIZ-PEREIRA; LACERDA, 2009).

Imerso no contexto descrito e adotando uma abordagem qualitativa do tipo estudo de caso, o presente trabalho propõe-se a investigar o tema da formação docente em um lócus 


\section{\#tear}

formativo específico, partindo das seguintes questões: como está organizada a estrutura curricular e quais são os aspectos formativos/temas desenvolvidos nas práticas pedagógicas do curso de Licenciatura em Química de uma universidade federal, localizada em uma cidade do interior do Rio Grande do Sul (CLQ-RS)? Quais são as convergências e divergências das visões de docentes e discentes no que tange ao referido curso?

\section{Elementos para a formação docente contemporânea}

A literatura da área educacional sinaliza para a necessidade de que a formação docente seja realizada considerando que toda a ação de ensino não terá apenas consequências pessoais (desenvolvimento social e emocional) e acadêmicas (desenvolvimento intelectual), mas também produzirá implicações políticas, expressas nos efeitos acumulados das experiências escolares sobre a vida dos sujeitos (ZEICHNER, 2008a). Nesse sentido, a formação docente não pode deixar de abarcar todas as consequências do ensino (pessoais, acadêmicas e políticas), nem mesmo abster-se de promover o ensino e a justiça social (ZEICHNER, 2008a). Essa ligação entre Educação e sociedade deve reforçar outras estruturas da prática dos professores, que devem: conhecer o conteúdo acadêmico pelo qual são responsáveis e saber conduzir o aprendizado dos mesmos; ter em vista as referências culturais e sociais apresentadas pelos estudantes; ter domínio e clareza sobre a condução das discussões em sala de aula, da avaliação discente e dos conhecimentos pedagógicos de base; saber como não limitar as chances de vida dos seus alunos; rejeitar o modelo transmissivo do conhecimento e da memorização.

Assim, a politicidade do ato educativo (SCOCUGLIA, 2005) extrapola a atuação docente circunscrita aos objetivos do programa escolar e da sala de aula expositora de conteúdos, concebendo a educação como um exercício de cidadania legítima (FREIRE, 2000). Esta corrente progressista tem visíveis afinidades com a luta por justiça social descrita por Zeichner (2008a, 2008b). Nessa perspectiva, a educação só faz sentido quando homens e mulheres assumirem-se como sujeitos que possuem a capacidade de saber, de aprender a construir e reconstruir, de serem e terem projetos (FREIRE, 2000, p. 40).

Os cursos de Licenciatura, na análise contemporânea, apresentam-se com estruturas hibridizadas que concebem a formação de professores por racionalidades distintas: técnica, prática e crítica (DINIZ-PEREIRA, 2002). As estruturas curriculares e as práticas formadoras garantem a convivência entre tais polos, no âmbito das instituições formadoras, ainda que haja desequilíbrios nessas relações (KRAHE, 2011). 
A racionalidade técnica concebe que a atividade docente pode ser realizada mediante uma abordagem instrumental, baseada na aplicação rigorosa de uma teoria científica, considerando que os atores seriam supostamente livres de valores, agentes neutros do processo (DINIZ-PEREIRA, 2002). Esse pode ser considerado o paradigma tradicional das licenciaturas, que adota a epistemologia da transmissão de saberes por parte do professor, enquanto a avaliação é baseada na reprodução do que foi transmitido (TAVARES; ALARCÃO, 2001).

A racionalidade prática concebe o trabalho docente como um processo complexo, guiado pelas decisões que ocorrem na prática dos profissionais e não controlado por uma simples sistematização técnica (DINIZ-PEREIRA, 2002). Nesse modelo, os professores decidem os comportamentos que devem ser aprendidos, tem maior margem para propor formas de pensar e construir os processos de ensino e aprendizagem.

A racionalidade crítica privilegia as facetas políticas da Educação, localizando-a histórica e socialmente, bem como focalizando as consequências para a vida dos sujeitos envolvidos no processo (DINIZ-PEREIRA, 2002). Aqui, o professor tem grande autonomia para atuar sobre o currículo, o ensino, a organização escolar e sua relação com a sociedade.

$\mathrm{Na}$ construção e reconstrução dos modelos que constituem as licenciaturas, há diferentes grupos de influência e decisão que interferem a partir dos processos de construção curricular (SACRISTÁN, 2000). Diferentes componentes emergem da força política oriunda da administração educacional, dividindo espaço com os demais grupos que participam das decisões curriculares, como as agências governamentais, os sindicatos, os estudantes, os especialistas, os pesquisadores em Educação etc.

\section{Metodologia}

A investigação ora apresentada é caracterizada como estudo de caso, considerando sua abordagem descritiva e heurística, que oferece uma exposição densa dos fenômenos explorados (MERRIAM, 1990). Buscamos identificar elementos contextuais, institucionais, subjetivos e outras relações derivadas destas, que caracterizam o enfoque qualitativo (ESTEBAN, 2010). Os movimentos de pesquisa realizados sobre o CLQ-RS focalizaram diferentes fontes de informação, com destaque para as visões dos estudantes, dos professores formadores e a estrutura curricular do curso.

O planejamento foi baseado nas fases da pesquisa qualitativa propostas por Latorre et al. (1996). Inicialmente, realizamos procedimentos exploratórios e definições de planejamento 
geral. As primeiras ações exploratórias foram pautadas pela identificação do problema, das questões de pesquisa, da revisão analítica inicial de documentos e de definições relativas aos referenciais teóricos.

Utilizamos a análise documental, que ao basear-se em fontes de dados persistentes ao longo do tempo, fornece um conjunto de informações que caracteriza o contexto de interesse (GUBA; LINCOLN, 1981; LÜDKE; ANDRÉ, 1986). Essa etapa incluiu: i. trabalhos científicos publicados em periódicos especializados, ou seja, a revisão da literatura propriamente dita; ii. documentos orientadores das políticas públicas e legislação relacionadas (BRASIL, 2001, 2002a, 2002b, 2009, 2015); iii. Projeto Pedagógico do Curso (PPC), títulos das disciplinas, ementas e percurso curricular; iv. indicadores extraídos do Censo da Educação Superior, também disponibilizados pelo INEP (2014a).

O estudo da estrutura curricular foi realizado tendo como referência os diferentes modelos de formação docente relatado na literatura, com base em suas racionalidades (técnica, prática e crítica). Este foi realizado mediante estudo preliminar das ementas e títulos das disciplinas, além de informações complementares do PPC. Foi possível, com isso, categorizarmos as disciplinas do curso, tendo como referência o trabalho de Gatti e Barreto (2009). Nesse sentido, foi possível quantificarmos as disciplinas, em termos de carga horária, em grupos distintos: grupo 1 (disciplinas gerais da base de conhecimentos teórico-práticos em Educação), grupo 2 (disciplinas da formação específica para a docência em Química) e grupo 3 (disciplinas que se referem ao conhecimento específico da área de Ciências Exatas e Ciências da Natureza).

O segundo momento da pesquisa, de exploração dos pontos de vista dos sujeitos do curso, foi pautado pela aplicação de questionários (por correio eletrônico) com dois grupos de informantes: i. professores do Núcleo Docente Estruturante (NDE), que deveriam ser atuantes nas questões curriculares e envolvidos em decisões sobre o perfil pretendido para os egressos e objetivos do curso; ii. alunos matriculados a partir da segunda metade do curso, pois estes teriam maior embasamento para contribuir com as questões de pesquisa.

Foi possível o contato com um grupo de 10 discentes (em fase final de curso e com condições de fornecer respostas mais embasadas sobre a estrutura e as práticas deste), apresentando o seguinte perfil geral: a fração majoritária era composta por mulheres (8 estudantes); houve maior frequência da faixa etária que compreendia o intervalo entre 18 e 24 anos (6 sujeitos); a totalidade da amostra autodeclarou-se branco(a), indicou o estado civil solteiro(a) e utiliza a internet como principal meio de obtenção de informação; apenas alguns 
estudantes afirmaram dominar outro idioma, incluindo a língua inglesa (2 estudantes) e a língua espanhola ( 2 estudantes); foi predominante o número de respondentes que estudou em escola pública durante o Ensino Médio (9 estudantes).

A amostra de docentes/formadores foi composta por 4 dos 5 professores pertencentes ao NDE do CLQ-RS. O grupo é composto por 2 homens e 2 mulheres, com faixas de idade bastante heterogêneas. Nenhum dos sujeitos é identificado com a área de Educação Química, estes atuam em áreas específicas da Química: Química Inorgânica, Química Analítica, FísicoQuímica e Química Orgânica. Além disso, a maior fração (3/4) dos professores de amostra participam do NDE por um período inferior a 5 anos.

Essa trajetória constituiu a fase de entrada no cenário, na qual negociamos com gestores do CLQ-RS o acesso às informações que são pertinentes ao escopo do estudo. A aproximação ocorreu, em um primeiro momento, por meio de correio eletrônico e, complementarmente, por contato telefônico.

A fase de coleta de dados com os informantes foi efetivada pelo envio e aplicação de questionários contendo questões abertas e fechadas ${ }^{1}$, inclusive tipo Likert (1976), que apresentam afirmações com as quais o sujeito expressa o seu grau de concordância/discordância em uma escala de cinco pontos. A fase de análise das respostas relativas às questões mencionadas foi baseada no cálculo de Ranking Médio (RM), conforme exemplos presentes na literatura da área de Educação em Ciências (BOHRER; FARIAS, 2013; PASSOS; DEL PINO, 2014; FONSECA; SANTOS, 2015).

No presente trabalho, atribuímos valores de 1 a 5 para cada opção de resposta, orientando os cálculos conforme a Figura 1. Para cada item, quanto mais o RM calculado se aproximar dos valores extremos (1 ou 5), maior será a concordância dos informantes com as respostas representadas por tais índices.

Figura 1 - Fórmula para o cálculo do Ranking Médio

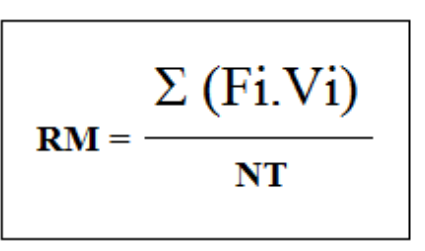

$\mathbf{R M}=$ Ranking Médio

$\mathbf{F i}=$ Frequência observada (por resposta e item)

$\mathbf{V i}=$ Valor de cada resposta

NT = Número total de informantes

Fonte: Adaptado de Bohrer e Farias (2013).

\footnotetext{
${ }^{1}$ Optamos, neste artigo, por explorarmos apenas os resultados derivados de questões fechadas, tendo em vista o limite de páginas determinado pelas normas desta revista.
} 


\section{\#tear}

$\mathrm{Na}$ construção dos instrumentos de coleta de dados, utilizamos como referência o questionário utilizado por Passos (2012), o questionário do Exame Nacional de Desempenho de Estudantes (ENADE) de 2011, disponibilizado pelo INEP (2014b), as DCNF (Brasil, 2002a), as DCNQ (Brasil, 2001) e a literatura da área de formação de professores. Os instrumentos foram validados independentemente por dois pesquisadores ligados à área do Ensino de Ciências. As respostas provenientes dos questionários e os dados dos documentos relativos ao CLQ-RS foram confrontados com os referenciais teóricos adotados, possibilitando a construção de inferências vinculadas ao escopo da investigação.

\section{Resultados e discussões}

O CLQ-RS foi criado no ano de 1961, passando por várias modificações curriculares e administrativas. Atualmente, habilita para a docência no Ensino Fundamental (Ciências) e no Ensino Médio (Química). As principais formas de acesso ao curso são o Processo Seletivo Único (vestibular) e o Processo Seletivo Seriado, com provas realizadas ao final de cada série do Ensino Médio. No total, são oferecidas 37 vagas anuais para os postulantes à licenciatura.

Nesse contexto e buscando a observância do CLQ-RS com tais prerrogativas, um novo PPC foi elaborado, sendo adotado a partir de 2004/2005. O reflexo desse processo resultou, então, na estrutura curricular vigente atualmente, que contém $3.375 \mathrm{~h}$ divididas em: $2.310 \mathrm{~h}$ de conteúdo técnico-científico; 405h em práticas educativas; 420h para estágio supervisionado; $240 \mathrm{~h}$ para atividades complementares (sendo $120 \mathrm{~h}$ de disciplinas complementares e $120 \mathrm{~h}$ de outras atividades). O tempo para integralização do curso é de 8 semestres (mínimo) a 12 semestres (máximo).

A análise curricular do CLQ-RS revelou o domínio das disciplinas relacionadas ao grupo 3 (disciplinas que se referem ao conhecimento específico da área de Ciências Exatas e Ciências da Natureza) em relação aos demais componentes formativos, com $60 \%$ da carga horária total. $\mathrm{O}$ grupo 2 (disciplinas voltadas à formação específica para a docência em Química, que engloba os conteúdos da escola básica, estágios de docência, metodologias e didática das ciências da natureza, tecnologias) foi o segundo mais presente na grade curricular, abrangendo aproximadamente $20 \%$ do tempo do curso e estando bem abaixo da categoria majoritária. Foi possível constatar que o outro bloco de disciplinas, denominado de grupo 1 (disciplinas gerais da base de conhecimentos teórico-práticos em Educação, o que inclui atividades curriculares eletivas, trabalho de conclusão de curso, tópicos de educação especial, componentes vinculados aos níveis e modalidades de ensino, gestão escolar, didática 
geral, disciplinas específicas/ vinculadas a áreas de conhecimento diversas que complementam a formação do professor) também ficam à margem, ocupando espaços e tempos ínfimos (somam, aproximadamente, 20\% da carga horária global).

Os dados curriculares obtidos fornecem indícios de um curso hibridizado, que destina uma pequena parcela de tempo para a formação prática na sala de aula do ensino básico e para as discussões críticas decorrentes desta, estando muito mais atrelado ao modelo da racionalidade técnica (DINIZ-PEREIRA, 2002). A grande quantidade de conteúdos químicos privilegiados pela grade curricular do CLQ-RS ajuda a compor uma formação sólida na área, como recomendado pelas DCNF (BRASIL, 2002a, 2015) e DCNQ (BRASIL, 2001). O problema é que esse formato tem caráter mais informativo do que formativo (BRASIL, 2001), tendendo a ocasionar a construção de habilidades profissionais insuficientes ou muito aquém do que a formação inicial (adequada para o ofício de professor) deveria oferecer.

No que se refere às contribuições formativas do CLQ-RS (Gráfico 1), há duas situações distintas, que podem ser analisadas com base nos valores de RM calculados: estudantes e docentes/formadores parecem reconhecer que haja contribuição do curso de licenciatura no quesito formação teórica em química (valores de RM são aproximadamente iguais e próximos de 5); quanto à contribuição do curso nos quesitos formação profissional e aquisição de cultura geral, os valores correspondentes de RM dos docentes/formadores são maiores do que aqueles verificados para os discentes. Nesse sentido, os dados denotam que a percepção dos estudantes com relação a tais aspectos formativos não parece ser tão positiva quanto à percepção dos professores/formadores, aproximando-se de nossas inferências anteriormente elaboradas, com base na categorização das disciplinas. 


\section{\#tear}

Gráfico 1 - Contribuições do CLQ-RS/ Visão de Alunos e Docentes.

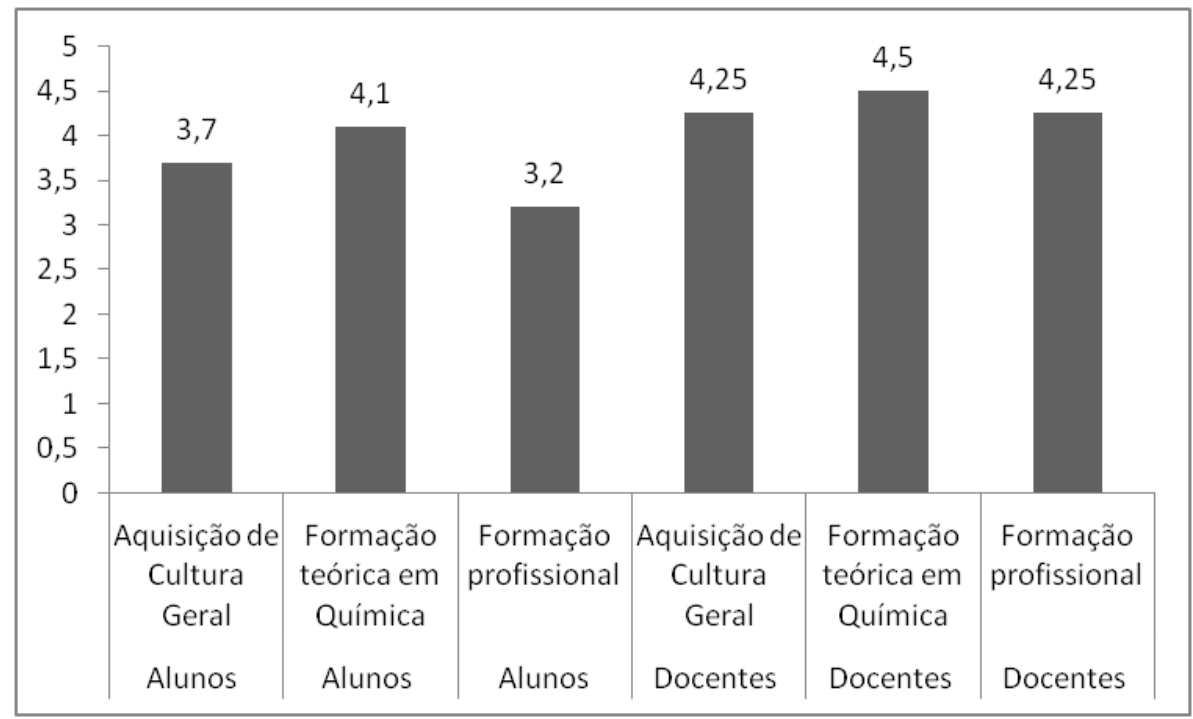

Fonte: Questionários respondidos por alunos e docentes.

Legenda: Os valores atribuídos às respostas foram os seguintes: 5-contribui amplamente; 4-contribui parcialmente; 2-contribui muito pouco; 1-não contribui. Os itens investigados estão descritos no gráfico.

O Gráfico 2 expressa a visão dos grupos investigados sobre a frequência com que ocorrem momentos de aprendizagem sobre diferentes temas indicados para o currículo das licenciaturas, segundo as DCNF (BRASIL, 2002a, 2015) e DCNQ (BRASIL, 2001) - itens 1.A até 1.L. Verificamos que as respostas dos discentes, comparadas às dos docentes/formadores, apresentam valores menores de RM, havendo um posicionamento aparentemente mais crítico por parte dos estudantes da licenciatura (que identifica maiores problemas no processo formativo). 


\section{\#tear \\ Revista de Educação, Ciência e Tecnologia}

Gráfico 2 - Visão dos informantes sobre os momentos de aprendizagem.

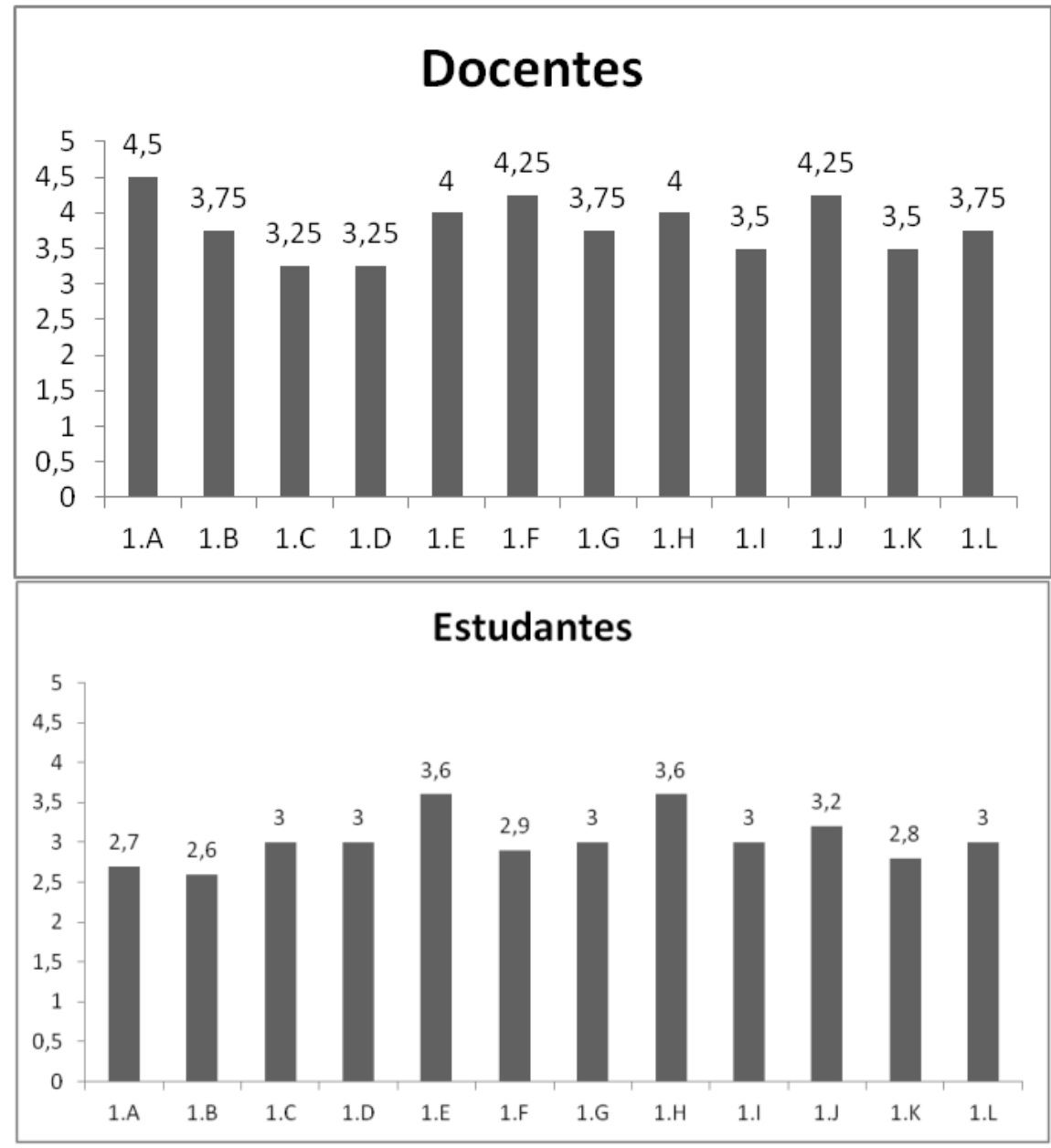

Fonte: Questionários respondidos pelos informantes.

Legenda: Os valores atribuídos às respostas foram os seguintes: 5-sempre; 4-muitas vezes; 3-não tenho opinião; 2-raramente; 1-nunca. As opções eram: 1.A- Postura crítica e reflexiva, sobre a função social, política e cultural do professor de química. 1.B- Visão crítica com relação ao papel social da Ciência e à sua natureza epistemológica, compreendendo o processo histórico-social de sua construção. 1.C- Conhecimento do fundamentos da pesquisa educacional e estar preparado para atuar como pesquisador no ensino de Química. 1.DCapacitação para produzir e avaliar diferentes recursos instrucionais e materiais didáticos. 1.E- Formação sólida e abrangente em conteúdos dos diversos campos da Química. 1.F- Conscientização sobre a importância de relacionar os conteúdos de química com outras áreas de conhecimento. 1.G- Articulação dos conhecimentos a serem ensinados na Educação Básica com os conhecimentos pedagógicos, didáticas e metodologias específicas e necessárias ao trabalho docente, considerados os diferentes níveis e modalidades de ensino. 1.H- Participação em eventos, cursos ou atividades de extensão, voltados ao ensino de Química ou atividades culturais diversificadas. 1.I- Desenvolvimento da autonomia profissional e intelectual, caracterizada pela curiosidade, criatividade e iniciativa na solução de problemas envolvendo o ensino de Química. 1.J- Importância da formação continuada para o processo de desenvolvimento profissional do professor. 1.K - Visão crítica sobre os fins da Educação Básica pautados pelo pleno desenvolvimento do educando, seu preparo para o exercício da cidadania e sua qualificação para o trabalho. 1.L- Contribuições e possibilidades da alfabetização científica e tecnológica para a formação do educando.

Inferimos que na perspectiva de grande parte dos estudantes, o CLQ-RS deixa de enfatizar assuntos que são primordiais para a profissão docente, tais como: função social e política do professor (1.A); visão crítica com relação ao papel social da Ciência e à sua natureza epistemológica (1.B); fundamentos da pesquisa educacional (1.C); articulação dos 


\section{\#tear}

conhecimentos a serem ensinados na Educação Básica com os conhecimentos pedagógicos, didáticas e metodologias (1.G); autonomia profissional (1.I).

A visão dos professores/formadores também é comparativamente mais positiva no que tange a outros aspectos, tais como: conscientização sobre a importância de relacionar os conteúdos de química com outras áreas de conhecimento (1.F); importância da formação continuada para o processo de desenvolvimento profissional (1.J); visão crítica sobre os fins da Educação Básica pautados pelo pleno desenvolvimento do educando, seu preparo para o exercício da cidadania e sua qualificação para o trabalho (1.K). Tais pontos representam, em boa medida, aspectos atualmente discutidos pela comunidade pesquisadores em Educação Química como elementos fundamentais para a qualificação da formação docente nessa área (PASSOS, 2012; FONSECA; SANTOS, 2016).

Os resultados verificados nas respostas dos estudantes parecem convergir com a análise curricular que discutimos anteriormente. Ao apontarem fragilidades, em seu curso de formação inicial, referentes principalmente a saberes atrelados às disciplinas voltadas aos conhecimentos pedagógicos que embasam a profissão docente, as respostas dos discentes tendem a apontar para a ocorrência de práticas pedagógicas formativas orientadas pela racionalidade técnica, ou seja, com enfoques relativamente afastados da prática da sala de aula e do ofício do professor (DINIZ-PEREIRA, 2002).

Há apenas dois pontos nos quais os grupos de estudantes e docentes/formadores apresentam respostas aproximadas (valores de RM) a essa questão, referentes à formação sólida e abrangente em conteúdos dos diversos campos da Química (1.E) e à ocorrência de participação em eventos, cursos ou atividades de extensão (1.H). Essas visões também apontam no mesmo sentido da análise da estrutura curricular desenvolvida acima, tendo em vista que esta já havia indicado o maior direcionamento da carga horária do curso para as áreas de conhecimento vinculadas à Química (incluindo Ciências Exatas e Ciências da Natureza).

\section{Considerações finais}

A investigação do CLQ-RS mostrou que existem diferentes problemas relacionados ao percurso curricular e à formação do professor de Química, sendo que a estrutura geral do curso parece estar orientada pela lógica da racionalidade técnica. Características da racionalidade prática aparentam estar presentes de forma hibridizada nas disciplinas voltadas à formação específica para a docência, já que estas concebem o trabalho docente como um 
processo complexo, guiado pelas decisões que ocorrem na prática dos profissionais e não controlado por uma simples sistematização técnica (DINIZ-PEREIRA, 2002). Há, ainda, a presença de disciplinas vinculadas aos conhecimentos educacionais, que ensejam um tratamento mais abrangente e politicamente situado do professor, o que provavelmente represente uma pequena contribuição dos aspectos constitutivos da racionalidade crítica.

Ressaltamos o fato de que as DCNF (BRASIL, 2002a, 2015) e as DCNQ (BRASIL, 2001) configuraram-se como fatores de intervenção política sobre o currículo analisado. Esse tipo de interferência, a política curricular, tem a intenção de incidir sobre a ordem dos conteúdos e sobre os códigos considerados válidos para o ensino (SACRISTÁN, 2000). Apesar de exercer influência, verificamos que ocorreram apropriações específicas que modificaram e adaptaram as diretrizes citadas, de modo que seus princípios não foram integralmente absorvidos.

As respostas de professores e alunos mostraram, em geral, que há expressiva diferença de opiniões sobre o curso. A visão discente é mais crítica, apontando deficiências no tratamento de fundamentos importantes para o exercício do magistério: elementos práticos e norteadores da autonomia profissional docente, a preparação didática e metodológica para o ensino básico.

Verificamos, ainda, que a visão discente aponta para a existência de maiores debilidades do curso de licenciatura estudado no que se refere à preparação voltada para aspectos da cultura geral contemporânea, parecendo indicar a ocorrência de processos formativos excessivamente endógenos, que não provocam o diálogo necessário do professor de Química em formação com outros temas e problemas sociais. Ao que parece, o funcionamento e a estruturação das disciplinas em tela deveriam proporcionar maior articulação entre os conhecimentos químicos, os conhecimentos pedagógicos e o contexto mais amplo da sociedade contemporânea.

A partir do que foi exposto, o presente trabalho procurou não apenas mostrar algumas inconsistências referentes ao curso que foi objeto de nosso estudo, mas problematizar a condição formativa das licenciaturas e propor que estas consigam efetuar sobreposições mais equilibradas entre o conhecimento químico, o conhecimento pedagógico/educacional e o caráter político/crítico da profissão docente. Ressaltamos que outras pesquisas, visando maior aprofundamento e que tenham foco sobre os processos formativos desta e de outras licenciaturas, são necessárias para que um conjunto de informações mais abrangentes seja efetivamente constituído sobre a formação inicial na docência em Química. 


\title{
\#tear
}

A observação direta dos processos de ensino-aprendizagem (da sala de aula e de seus atores), por exemplo, não foi considerada neste estudo, sendo uma alternativa possivelmente reveladora para investigações futuras. Ponderamos, ainda, que o número relativamente pequeno de informantes que foram interpelados também sugere que o estudo, aqui apresentado, guarda limitações no que tange à representatividade das visões discutidas, ainda que esse fato não torne as inferências elaboradas menos relevantes e válidas, no contexto das pesquisas educacionais sobre formação docente. Justificamos esse posicionamento tendo em vista que os objetivos desta pesquisa foram atingidos, ou seja, foi possível identificarmos alguns dos elementos indicativos da conjuntura do CLQ-RS, com base em critérios prédeterminados e fontes de informações delimitadas com base em estudos correlatos.

Acreditamos que os cursos de licenciatura devem preparar os futuros profissionais para o contexto de dificuldades estruturais que ultrapassam as questões práticas internas às salas de aula, as metodologias de ensino e a burocracia escolar. A consciência crítica a ser construída durante a graduação deve possibilitar o enfrentamento de desafios inerentes ao contexto da profissão docente, que seja resistente tanto às dificuldades mais rotineiras e mais imediatas da Educação Básica, quanto às representações socioculturalmente construídas sobre as possibilidades e limites do trabalho docente, a importância e a abrangência deste na sociedade contemporânea.

\section{DIFFERENT LOOKS ON PEDAGOGICAL PRACTICES IN CHEMISTRY TEACHER TRAINING DEGREE: A CASE STUDY}

\begin{abstract}
This paper presents a case study concerning teacher education in the field of Chemistry. The objectives are to identify and problematize some of the elements that make up a curricular structure and the pedagogical practices of the Teacher Training Degree in Chemistry of a federal university located in the state of Rio Grande do Sul - Brazil. The research is built upon the following data: the perspectives of professors and students surveyed through questionnaires answered by students in the final stages of the program and faculty members of the Structuring Faculty Council; the pedagogical plan of the program, as well as documents which enable the characterization and analysis of the case. The disciplines were categorized based on the literature, which allowed the determination of the privileged areas of knowledge in terms of hours in the curricular structure. Results show a greater similarity of the teacher training program to the technical-rationality model, although in a hybridized form. The evidence also points to the need for curricular reformulations that allow greater interaction of pedagogical and educational knowledge with the specificities of the chemical knowledge, allowing greater contributions of the course for the professional exercise of its graduates.
\end{abstract}

Keywords: Teacher Education in Chemistry. Curriculum. Pedagogical Practices. 


\section{Referências}

ARRIGO, V.; LORENCINI-JÚNIOR, A.; BROIETTI, F. C. D. A autoscopia bifásica integrada ao microensino: uma estratégia de intervenção reflexiva na formação de professores de química. Investigações em Ensino de Ciências, v.22, n. 1, p. 01-22, 2017.

BARCELOS, N. N. S.; VILLANI, A. Troca entre universidade e escola na formação docente: uma experiência de formação inicial e continuada. Ciência \& Educação, Bauru, v.12, n.1, p. 73-97, 2006.

BARDIN, L. (2010). Análise de Conteúdo. Lisboa: Edições 70, 2010. 281 p.

BEJARANO, N. R. R.; CARVALHO, A. M. P. de. Tornando-se professor de ciências: crenças e conflitos. Ciência \& Educação, Bauru, v.9, n.1, p. 1-15, 2003.

BOHRER, T. R. J.; FARIAS, M. E. As Teorias Implícitas de Aprendizagem dos estudantes/bolsistas do curso de Ciências Biológicas do Programa Institucional de Bolsa de Iniciação à Docência - PIBID. In: IX Encontro Nacional de Pesquisa em Educação em Ciências, Águas de Lindóia, 2013. Atas do IX Encontro Nacional de Pesquisa em Educação em Ciências - IX ENPEC, Águas de Lindóia, SP - 10 a 14 de Novembro de 2013.

BRASIL. Conselho Nacional de Educação, Parecer CNE/CES 1.303, de 06 de novembro de 2001. Aprova o projeto de resolução para as Diretrizes Curriculares para os cursos de Bacharelado e Licenciatura em Química.

BRASIL. Conselho Nacional de Educação, Resolução CNE/CP n.1, de 18 de fevereiro de 2002a. Institui Diretrizes Curriculares Nacionais para a Formação de Professores da Educação Básica, em nível superior, curso de licenciatura, de graduação plena.

BRASIL. Conselho Nacional de Educação, Resolução CNE/CP n. 2, de 19 de fevereiro de 2002b. Institui a duração e a carga horária dos cursos de licenciatura, de graduação plena, de formação de professores da Educação Básica em nível superior.

BRASIL. Conselho Nacional de Educação. Resolução CNE/CP 02/2015, de $1^{\circ}$ de julho de 2015.

BRASIL. Decreto $\mathbf{n}^{\mathbf{0}}$ 6.755, de 29 de janeiro de 2009. Institui a Política Nacional de Formação de Profissionais do Magistério da Educação Básica, disciplina a atuação da Coordenação de Aperfeiçoamento de Pessoal de Nível Superior - CAPES no fomento a programas de formação inicial e continuada, e dá outras providências. Diário Oficial da União. Brasília: Casa Civil da Presidência da República.

CAMARGO, E. P. de; NARDI, R. Dificuldades e alternativas encontradas por licenciandos para o planejamento de atividades de ensino de óptica para alunos com deficiência visual.

Revista Brasileira de Ensino de Física, São Paulo, v.29, n.1, p. 115-126, 2007. 
CANEN, A.; ANDRADE, L. T. de. Construções Discursivas sobre Pesquisa em Educação: o que falam professores formadores universitários. Educação \& Realidade, Porto Alegre, v.30, n.1, 2005.

CANEN, A.; XAVIER, G. P. de M. Multiculturalismo, pesquisa e formação de professores: o caso das Diretrizes Curriculares para a Formação Docente. Ensaio: avaliação das políticas públicas em Educação, Rio de Janeiro, v.13, n.48, p. 333-344, 2005.

CHASSOT, A. Alfabetização científica: questões e desafios para a educação. Ijuí: Editora Unijuí, 2000. 432 p.

DIAS, R. E.; LOPES, A.C. Competências na formação de professores no Brasil: o que (não) há de novo. Educação \& Sociedade, Campinas, v. 24, n. 85, p. 1155-1177, dez., 2003.

DINIZ-PEREIRA, J. E. A Pesquisa dos Educadores como estratégia para construção de modelos críticos de formação docente. In: DINIZ-PEREIRA, J. E.; ZEICHNER, K. M. A (orgs.). Pesquisa na Formação e no Trabalho Docente. Belo Horizonte: Autêntica, 2002. 200 p.

DINIZ-PEREIRA, J. E.; LACERDA, M. P. de. Possíveis significados da pesquisa na prática docente: ideias para fomentar o debate. Educação \& Sociedade, Campinas, v.30, n.109, p. 1229-1242, 2009.

DURAND, M.; SAURY, J. ; VEYRUNES, P. Relações fecundas entre pesquisa e formação docente: elementos para um programa. Cadernos de Pesquisa, São Paulo, v.35, n.125, p. 37 $62,2005$.

ECHEVERRÍA, A. R.; ZANON, L. B. (org.). Formação superior em Química no Brasil. Ijuí: Editora Unijuí, 2010. 272 p.

ESTEBAN, M. P. S. Pesquisa Qualitativa em Educação: Fundamentos e Tradições. Porto Alegre: AMGH, 2010. 268 p.

FONSECA, C. V.; SANTOS, F. M. T. O curso de licenciatura em química da UFRGS: estudo da estrutura curricular e de aspectos constitutivos da formação docente. Alexandria: Revista de Educação em Ciência e Tecnologia, Florianópolis, v. 8, n. 3, p. 81-111, nov. 2015.

FONSECA, C. V.; SANTOS, F. M. T. Educação em química, formação e trabalho docente: revisão de pesquisas brasileiras (2002-2015). Investigações em Ensino de Ciências, v. 21, p. 179-199, 2016.

FRANCO, M. L. P. B. Análise de Conteúdo. Brasília: Líber Livro Editora, 2008. 3. ed. 80 p. (Série Pesquisa; v. 6).

FREIRE, P. Pedagogia da Indignação: cartas pedagógicas e outros escritos. São Paulo: Editora UNESP, 2000.

FREITAS, H. C. L. A (nova) política de formação de professores: a prioridade postergada. Educação \& Sociedade, Campinas, v. 28, n. 100 - Especial, p. 1203-1230, out., 2007. 
FREITAS, H. C. L. Formação de professores no Brasil: 10 anos de embate entre projetos de formação. Educação \& Sociedade, Campinas, v. 23, n. 80, p. 137-168, Campinas, set., 2002.

GALIAZZI, M. do C.; MORAES, R. Educação pela pesquisa como modo, tempo e espaço de qualificação da formação de professores de ciências. Ciência \& Educação, Bauru, v.8, n.2, p. 237-252, 2002.

GARCIA, M. M. A. Textos e Contextos na Reforma das Licenciaturas: o caso da UFPel. Educação \& Realidade, Porto Alegre, v.35, n.2, p.229-252, maio/agosto, 2010.

GARCIA, I. T. S.; KRUGER, V. Implantação das diretrizes curriculares nacionais para formação de professores de química em uma instituição federal de ensino superior: desafios e perspectivas. Química Nova, São Paulo, v.32, n.8, p.2218-2224, 2009.

GATTI, B. A.; BARRETO, E. S. de S. (coords.). Professores do Brasil: impasses e desafios. Brasília: UNESCO, 2009. 294 p.

GAUCHE, R. SILVA, R. R. da; BAPTISTA, J. de A.; SANTOS, W. L. P. dos; MÓL, G. de S.; MACHADO, P. F. L.. Formação de Professores de Química: Concepções e Proposições. Química Nova na Escola, São Paulo, n.27, fev., 2008.

GIANOTTO, D. E. P.; DINIZ, R. E. da S. Formação inicial de professores de Biologia: a metodologia colaborativa mediada pelo computador e a aprendizagem para a docência. Ciência \& Educação, Bauru, v.16, n.3, p. 631-648, 2010.

GUBA, E. G.; LINCOLN, Y. S. Effective Evaluation. San Francisco: Jossey Bass, 1981.

HILA, C. V. D. O gênero artigo de opinião: diagnóstico e intervenção na formação inicial de professores de português. Trabalhos em Linguística Aplicada, Campinas, v.47, n.1, p. 183$201,2008$.

INEP. Instituto Nacional de Estudos e Pesquisas Educacionais Anísio Teixeira, 2014a. Disponível em: <http://portal.inep.gov.br/superior-censosuperior-sinopse>. Acesso em 31 mar. 2014.

INEP. Instituto Nacional de Estudos e Pesquisas Educacionais Anísio Teixeira, 2014b. Disponível em: <http://portal.inep.gov.br/enade>. Acesso em: 05 abr. 2014.

KASSEBOEHMER, A. C.; FERREIRA, L. H. O espaço da prática de ensino e do estágio curricular nos cursos de formação de professores de química das ies públicas paulistas.

Química Nova, São Paulo, v.31, n.3, p.694-699, 2008.

KRAHE, E. D. Reformas na estrutura curricular das licenciaturas. In: LEITE, D.; GENRO, M. E. H.; BRAGA, A. M. e S. Inovação e Pedagogia Universitária. Porto Alegre: Editora da UFRGS, 2011. $256 \mathrm{p}$.

LATORRE, A.; DEL RINCÓN, D.; ARNAL, J. Bases Metodológicas de la Investigación Educativa. Barcelona: GR92, 1996. 
LENOIR, Y. Pesquisar e formar: repensar o lugar e a função da prática de ensino. Educação \& Sociedade, Campinas, v.27, n.97, p. 1299-1325, 2006.

LIKERT, R. Una técnica para medir actitudes. In: Summers, G. F.(ed.) Medición de actitudes. México: Editorial Trilias, 1976. p. 182-191.

LÜDKE, M.; ANDRÉ, M. Pesquisa em educação: abordagens qualitativas. São Paulo: EPU, 1986.

LÜDKE, M.; CRUZ, G. B. da. Aproximando universidade e escola de educação básica pela pesquisa. Cadernos de Pesquisa, São Paulo, v.35, n.125, p. 81-109, 2005.

MALDANER, O. A. A formação inicial e continuada de professores de Química: professores/pesquisadores. 4. ed. Ijuí: Editora Unijuí, 2013.

MASSENA, E. P.; MONTEIRO, A. M. F. da C. Concepções sobre currículo de formadores de professores: o curso de licenciatura em Química do Instituto de Química da Universidade Federal do Rio de Janeiro. Química Nova, São Paulo, v.34, n.8, p.1476-1484, 2011.

MERRIAM, S. B. Case Study Research in Education. Oxford: University Press, 1990.

MESQUITA, N. A. da S.; CARDOSO, T. M. G.; SOARES, M. H. F. B. O projeto de educação instituído a partir de 1990: caminhos percorridos na formação de professores de Química no Brasil. Química Nova, v. 36, n. 1, p. 195-200, 2013.

PASSOS, C. G. O Curso de Licenciatura em Química da UFRGS: conquistas e desafios frente à reformulação curricular de 2005. 2012. Tese de Doutorado, Instituto de Química, Universidade Federal do Rio Grande do Sul, Porto Alegre, 2012.

PASSOS, C. G.; DEL PINO, J. C. Reformulações curriculares do Curso de Licenciatura em Química da UFRGS: influências, contextos e práticas. Alexandria, Revista de Educação em Ciência e Tecnologia, v.7, n.1, p.209-234, maio 2014.

PEREIRA, J. B.; CAMPOS, M. L. A. de M.; NUNES, S. M. T.; ABREU, D. G. de. Um panorama sobre a abordagem ambiental no currículo de cursos de formação inicial de professores de química da região sudeste. Química Nova, São Paulo, v.32, n.2, p.511-517, 2009.

PINHEIRO, A. N.; MEDEIROS, E. de L.; OLIVEIRA, A. C. Estudo de casos na formação de professores de química. Química Nova, São Paulo, v.33, n.9, p.1996-2002, 2010.

RUSSEL, T. D. R.; VEIT, M. H. D. Estágio Docente: análise de interações sociais em sala de aula. Educação \& Realidade, Porto Alegre, v.36, n.1, 2011.

SACRISTÁN, J. G. O Currículo: uma reflexão sobre a prática. 3. ed. Porto Alegre: Artmed, 2000. 352 p.

SANGIOGO, F. A.; WOYCIECHOSWSKY, R.; ROSA, S. A. da; MALDANER, O. A. A pesquisa educacional como atividade curricular na formação de licenciandos de química.

Ciência \& Educação, Bauru, v.17, n.3, p. 523-540, 2011. 
SANTOS, S.; INFANTE-MALACHIAS, M. E. Interdisciplinaridade e resolução de problemas: algumas questões para quem forma futuros professores de ciências. Educação \& Sociedade, Campinas, v.29, n.103, p. 557-579, 2008.

SANTOS, W. L. P. dos; SCHNETZLER, R. P. Educação em química: compromisso com a cidadania. 4. ed. Ijuí: Editora Unijuí, 2010. 160 p.

SCOCUGLIA, A. C. As reflexões curriculares de Paulo Freire. Revista Lusófona de Educação, n.6, p.81-92, 2005.

SILVA, L. F.; CARVALHO, L. M. de. A temática ambiental e as diferentes compreensões dos professores de física em formação inicial. Ciência \& Educação, Bauru, v.18, n.2, p. 369$383,2012$.

SILVA, T. N.; FARIAS, C. R. O. Análise da inserção das questões ambientais em dois cursos de licenciatura em química de uma universidade pública. Investigações em Ensino de Ciências, v. 22, n. 3, p. 80-101, 2017.

TAVARES, J. ; ALARCÃO, I. Paradigmas de formação e investigação no ensino superior para o terceiro milênio. In: ALARCÃO, I. (org.). Escola Reflexiva e Nova Racionalidade. Porto Alegre: Artmed, 2001. 44 p.

ZEICHNER, K. M. Uma análise crítica sobre a "reflexão" como conceito estruturante na formação docente. Educação \& Sociedade, Campinas, v.29, n.103, p.535-554, mai./ago., 2008a.

ZEICHNER, K. M. A Formação de Professores para a justiça social em tempos de incerteza e desigualdades crescentes. In: DINIZ-PEREIRA, J. E.; ZEICHNER, K. M. A. (orgs.). Justiça Social - Desafio para a Formação de Professores. Belo Horizonte: Autêntica, 2008b. 168 p.

ZEICHNER, K. M.; DINIZ-PEREIRA, J. E. Pesquisa dos educadores e formação docente voltada para a transformação social. Cadernos de Pesquisa, São Paulo, v.35, n.125, p. 63-80, 2005. 